\title{
Analytical Research On The Accident Risk In Three Industries Of China And USA In The Period Of 2006-2010
}

\author{
Zongzhi Wu \\ China Academy of Safety Science and Technology \\ Beijing 100012, China \\ Shengzhu Zhang, Mingrong Zeng \\ China Academy of Safety Science and Technology \\ Beijing 100012, China \\ E-mail:zhangshengzh5168@163.com
}

\begin{abstract}
The related data analysis of China and USA shows that the work-related injuries are closely related to the proportion of each industry. High-incidence period is often in the period when the proportion of the secondary industry rises. Increasing proportion of the tertiary industry does good to decrease the number of employees in highly risky industries and lower accident hazard. Effective channels attributable to improving safety situation are to change industry structure, develop the tertiary industry and plan three industries development.
\end{abstract}

Key words: Industrial structure; Risk analysis; Accident; Safe development

\section{6-2010 年中国和美国三次产业事故风险分析研究}

吴宗之 张圣柱 ${ }^{*}$ 曾明荣

中国安全生产科学研究院, 北京 100012

摘要: 中美两国相关数据分析表明, 工伤事故情况与各产业的比重密切相关, 事故高发期多发生在 第二产业比重上升期。第三产业比重的增加有利于减少高危行业从业人员数量、降低事故风险。转 变产业结构、大力发展第三产业、合理统筹三次产业发展是促进安全发展的有效途径。

关键词: 产业结构, 风险分析, 事故, 安全发展

1. 引言

安全生产水平是衡量一个国家现代文明程度 的重要指标。近年来, 我国安全生产形势总体趋于 稳定，表现在事故总量下降，工矿商贸行业安全生 产状况趋于好转，建筑、交通、烟花爆竹和民爆器 材等相关行业和领域的安全工作取得成效; 但另一 方面安全生产形势依然十分严峻，与欧盟、美国和 日本等发达国家相比, 我国生产事故总量较大, 重 特大事故频繁发生, 职业危害严重。由对各产业事 故风险的分析可知, 以采矿业、建筑业和制造业为 代表的第二产业其事故风险较高, 第一产业和第三 产业的事故风险较低。大力发展低风险产业, 尤其 是第三产业, 不仅有利于促进经济结构的优化升
级、提高经济发展的现代化水平, 同时由于大多数 服务业的事故风险较低、就业容量大, 能在扩大就 业的同时改善安全生产状况。1-4 本文基于三次产业 的发展过程, 对比现阶段我国与美国在安全生产方 面存在的差距, 分析各产业事故风险特点, 探讨转 变产业结构的重要性。

2. 产业事故风险分析

\section{1. 我国三次产业事故风险分析}

2006-2010 年我国工矿商贸事故按国民经济行 业划分十万人死亡率如表 1 所示。5,6 
表 1 2006-2010 年各行业十万人死亡率

\begin{tabular}{|c|c|c|c|c|c|c|}
\hline 类别 年份 & 2006 & 2007 & 2008 & 2009 & 2010 & 5 年平均 \\
\hline 农、林、牧、渔业 & 3.28 & 2.31 & 2.37 & 2.81 & 2.58 & 2.67 \\
\hline 采矿业 & 135.55 & 114.05 & 100.51 & 75.33 & 65.91 & 98.27 \\
\hline 制造业 & 9.98 & 10.10 & 9.69 & 8.58 & 8.15 & 9.30 \\
\hline 电力、燃气及水的生产和供应业 & 10.12 & 10.48 & 11.42 & 9.33 & 6.76 & 9.62 \\
\hline 建筑业 & 27.98 & 28.29 & 27.82 & 23.44 & 21.85 & 25.88 \\
\hline 交通运输、仓储和邮政业 & 3.65 & 3.29 & 3.69 & 3.34 & 2.98 & 3.39 \\
\hline 信息传输、计算机服务和软件业 & 3.12 & 2.92 & 3.33 & 2.76 & 1.99 & 2.82 \\
\hline 批发和零售业 & 2.49 & 2.27 & 2.53 & 2.57 & 1.94 & 2.36 \\
\hline 住宿和餐饮业 & 2.83 & 2.33 & 2.86 & 3.27 & 2.10 & 2.68 \\
\hline 金融业 & 0.13 & 0.06 & 0.09 & 0.02 & 0.04 & 0.07 \\
\hline 房地产业 & 2.28 & 2.18 & 2.42 & 2.62 & 1.84 & 2.27 \\
\hline 租赁和商务服务业 & 7.30 & 9.01 & 6.64 & 5.40 & 4.48 & 6.57 \\
\hline 科学研究、技术服务和地质勘查业 & 2.32 & 2.94 & 2.58 & 1.25 & 1.30 & 2.08 \\
\hline 水利、环境和公共设施管理业 & 3.13 & 6.42 & 4.63 & 4.42 & 5.07 & 4.73 \\
\hline 居民服务和其他服务业 & 50.40 & 75.20 & 58.96 & 51.53 & 40.37 & 55.29 \\
\hline 教育 & 0.12 & 0.12 & 0.15 & 0.10 & 0.07 & 0.11 \\
\hline 卫生、社会保障和社会福利业 & 0.20 & 0.25 & 0.24 & 0.13 & 0.05 & 0.17 \\
\hline 文化、体育和娱乐业 & 1.63 & 1.60 & 3.86 & 3.24 & 2.89 & 2.64 \\
\hline 公共管理和社会组织 & 0.02 & 0.11 & 0.09 & 0.11 & 0.06 & 0.08 \\
\hline 全部行业平均 & 12.91 & 12.15 & 11.17 & 9.18 & 8.13 & 10.71 \\
\hline
\end{tabular}

注: 1 . 万万人死亡率由各行业死亡人数和就业人数求得, 各行业死亡人数数据来源于国家安监总局 2006-2011 年事故统计 年报, 各行业就业人数数据来源于 2006-2011 年中国劳动统计年鉴; 2. 部分行业因未充分将农民工计入就业人数导致十万人死亡率偏高, 统计数据不包括交通事故; 3.行业分类参照 GB/T 4754-2011《国民经济行业分类》。

由表 1 可知, 我国不同行业事故风险差异巨大。 各行业 2006-2010 年 5 年平均十万人死亡率中, 最 高的是采矿业, 达 98.27 , 是最低的金融业(十万人 死亡率为 0.07 )的 1400 余倍，其次分别是居民服务 和其他服务业、建筑业、电力、燃气及水的生产和 供应业以及制造业，除居民服务和其他服务业属第 三产业外，其他均属于第二产业。第一产业的十万 人死亡率较低。
第二产业中, 采矿业的十万人死亡率是全行业 中最高的, 建筑业的十万人死亡率为 25.88 , 电力、 燃气及水的生产和供应业与制造业的十万人死亡 率在 9 10 之间，第二产业事故风险最高。

第三产业中，居民服务和其他服务业的十万人 死亡率最高, 达 55.29, 远超过建筑业, 其他行业 的十万人死亡率均较低, 其中租赁和商务服务业的 十万人死亡率为 6.57 , 水利、环境和公共设施管理 业的十万

表 2 2006-2010 年我国部分行业一次死亡 10 人以上事故情况

\begin{tabular}{|c|c|c|c|c|c|c|c|c|c|c|}
\hline 时间 & 2006 & & 2007 & & 2008 & & 2009 & & 2010 & \\
\hline 类别 & $\begin{array}{l}\text { 事 故 } \\
\text { 起数 }\end{array}$ & $\begin{array}{l}\text { 所 占 } \\
\text { 比例 } \\
(\%)\end{array}$ & $\begin{array}{l}\text { 事 故 } \\
\text { 起数 }\end{array}$ & $\begin{array}{l}\text { 所 占 } \\
\text { 比例 } \\
(\%)\end{array}$ & $\begin{array}{l}\text { 事 故 } \\
\text { 起数 }\end{array}$ & $\begin{array}{l}\text { 所 占 } \\
\text { 比例 } \\
(\%)\end{array}$ & $\begin{array}{l}\text { 事 故 } \\
\text { 起数 }\end{array}$ & $\begin{array}{l}\text { 所 占 } \\
\text { 比例 } \\
(\%)\end{array}$ & $\begin{array}{l}\text { 事 故 } \\
\text { 起数 }\end{array}$ & $\begin{array}{l}\text { 所 占 } \\
\text { 比例 } \\
(\%)\end{array}$ \\
\hline 煤矿和非煤矿山 & 41 & 42.7 & 30 & 35.3 & 41 & 42.3 & 24 & 35.8 & 26 & 30.6 \\
\hline 建筑业 & 1 & 1.0 & 7 & 8.2 & 5 & 5.2 & 4 & 6.0 & 6 & 7.1 \\
\hline 工矿商贸合计 & 48 & 50.0 & 44 & 51.8 & 50 & 51.5 & 33 & 49.3 & 37 & 43.5 \\
\hline
\end{tabular}

注：事故数据来源于国家安监总局事故统计年报。

Published by Atlantis Press

Copyright: the authors 
人死亡率为 4.73 , 交通运输、仓储和邮政业的十万 人死亡率为 3.39 , 信息传输、计算机服务和软件业、 批发和零售业、住宿和餐饮业、房地产业、科学研 究、技术服务和地质勘查业和文化、体计算机服务 和软件业、批发和零售业、住宿和餐饮业、房地产 业、科学研究、技术服务和地质勘查业和文化、体 育和娱乐业的十万人死亡率在 $2 \sim 3$ 之间，卫生、

由表 2 可知, 工矿商贸行业所发生一次死亡 10 人以上事故占全国所发生重特大事故（2006-2010 年分别为 96 起、85 起、97 起、67 起、85 起) 的 比例一直在 50\%左右, 而煤矿和非煤矿山发生的一 次死亡 10 人以上事故又占工矿商贸行业重特大事 故的较大部分, 表明煤矿和非煤矿山开采容易导致
社会保障和社会福利业与教育的十万人死亡率更 低, 在 $0.1 \sim 0.2$ 之间, 金融业与公共管理和社会组 织的十万人死亡率最低, 均小于 0.1 。第三产业中 的大多数行业事故风险远低于第二产业。

2006-2010 年我国部分行业一次死亡 10 人以上 事故情况如表 2 所示。

重特大事故, 给安全生产工作带来巨大负面影响, 建筑业和其他行业的重特大事故相对较少。

\section{2. 美国三次产业事故风险分析}

2006-2010 年美国各行业十万人死亡率如表 3 所示。

表 3 2006-2010 年美国各行业十万人死亡率

\begin{tabular}{|c|c|c|c|c|c|c|c|c|c|c|c|c|}
\hline 时间 & 2006 & & 2007 & & 2008 & & 2009 & & 2010 & & 5 年平均 & \\
\hline 类别 & $\begin{array}{l}\text { 死亡 } \\
\text { 人数 } \\
\text { (人) }\end{array}$ & $\begin{array}{l}\text { 死亡 } \\
\text { 率 }\end{array}$ & $\begin{array}{l}\text { 死亡 } \\
\text { 人数 } \\
\text { (人) }\end{array}$ & $\begin{array}{l}\text { 死亡 } \\
\text { 率 }\end{array}$ & $\begin{array}{l}\text { 死亡 } \\
\text { 人数 } \\
\text { (人) }\end{array}$ & $\begin{array}{l}\text { 死亡 } \\
\text { 率 }\end{array}$ & $\begin{array}{l}\text { 死亡 } \\
\text { 人数 } \\
\text { (人) }\end{array}$ & $\begin{array}{l}\text { 死亡 } \\
\text { 率 }\end{array}$ & $\begin{array}{l}\text { 死亡 } \\
\text { 人数 } \\
\text { (人) }\end{array}$ & $\begin{array}{l}\text { 死亡 } \\
\text { 率 }\end{array}$ & $\begin{array}{l}\text { 死亡 } \\
\text { 人数 } \\
\text { (人) }\end{array}$ & $\begin{array}{l}\text { 死亡 } \\
\text { 率 }\end{array}$ \\
\hline \multicolumn{13}{|l|}{ 1. 商品生产 } \\
\hline 农林渔牧业 & 655 & 30.0 & 585 & 27.9 & 651 & 29.4 & 551 & 26.0 & 621 & 27.9 & 613 & 28.24 \\
\hline 采矿业 & 192 & 28.1 & 183 & 25.1 & 175 & 18.0 & 101 & 12.7 & 172 & 19.8 & 165 & 20.74 \\
\hline 建筑业 & 1239 & 10.9 & 1204 & 10.5 & 969 & 9.6 & 816 & 9.7 & 774 & 9.8 & 1000 & 10.10 \\
\hline 制造业 & 456 & 2.8 & 400 & 2.5 & 404 & 2.5 & 304 & 2.2 & 329 & 2.3 & 379 & 2.46 \\
\hline \multicolumn{13}{|l|}{ 2. 服务业 } \\
\hline 批发贸易 & 222 & 4.9 & 207 & 4.7 & 175 & 4.2 & 186 & 4.9 & 191 & 4.9 & 196 & 4.72 \\
\hline 零售贸易 & 359 & 2.2 & 348 & 2.1 & 290 & 2.0 & 291 & 2.1 & 311 & 2.2 & 320 & 2.12 \\
\hline 运输仓储 & 860 & 16.8 & 890 & 16.9 & 762 & 14.2 & 579 & 12.1 & 661 & 13.7 & 750 & 14.74 \\
\hline 信息与传媒 & 66 & 2.0 & 79 & 2.3 & 45 & 1.4 & 32 & 1.1 & 43 & 1.5 & 53 & 1.66 \\
\hline $\begin{array}{l}\text { 金融、保险、地产、 } \\
\text { 租赁等 }\end{array}$ & 126 & 1.2 & 119 & 1.2 & 103 & 1.0 & 101 & 1.1 & 113 & 1.3 & 112 & 1.16 \\
\hline $\begin{array}{l}\text { 科技、管理及行政 } \\
\text { 服务 }\end{array}$ & 459 & 3.2 & 476 & 3.1 & 389 & 2.7 & 394 & 2.9 & 364 & 2.6 & 416 & 2.90 \\
\hline $\begin{array}{l}\text { 教育、健康及社会 } \\
\text { 服务 }\end{array}$ & 178 & 0.9 & 149 & 0.7 & 137 & 0.7 & 136 & 0.7 & 171 & 0.9 & 154 & 0.78 \\
\hline $\begin{array}{l}\text { 艺术、娱乐及住宿 } \\
\text { 餐饮 }\end{array}$ & 265 & 2.3 & 260 & 2.2 & 233 & 2.2 & 216 & 2.1 & 238 & 2.3 & 242 & 2.22 \\
\hline 其他 & 183 & 2.6 & 175 & 2.5 & 172 & 2.5 & 166 & 2.7 & 192 & 3.0 & 178 & 2.66 \\
\hline 3. 政府公共管理 & 520 & 2.4 & 545 & 2.5 & 522 & 2.3 & 450 & 1.9 & 484 & 2.2 & 504 & 2.26 \\
\hline
\end{tabular}

注: 1.数据来源于美国劳工局 2006-2011 年的统计数据

2. 数据不包含军事领域, 从业人员年龄不小于 16 周岁。

由表 3 可知, 美国第一产业的十万人死亡率最 高, 达 28.24, 就第二产业和第三产业与我国相比 较, 尽管美国总体事故死亡人数远少于我国, 但其 各行业事故风险特点与我国相似。采矿业事故导致 的死亡人数虽较少, 但由于从业人数少, 其十万人 死亡率非常高, 平均达 20.74, 建筑业事故造成的 死亡人数最多, 达 1000 人/年, 十万人死亡率也较 高, 平均达 10.10 , 制造业事故风险较低, 十万人 死亡率为 2.46。第三产业中, 除运输仓储业的十万
人死亡率(达 14.74)较高外, 其他行业的十万人死亡 率均较低, 其中批发贸易的十万人死亡率为 4.72 , 科技、管理及行政服务、政府公共管理、艺术、娱 乐及住宿餐饮和零售贸易的十万人死亡率在 $2 \sim 3$ 之间, 信息与传媒和金融、保险、地产、租赁等行 业的十万人死亡率在 1 2 之间, 教育、健康及社 会服务业的十万人死亡率小于 1 。总体上讲, 第二 产业事故风险远高于第三产业。

Published by Atlantis Press

Copyright: the authors 


\section{3. 产业事故风险差异性}

不同产业在工作环境、作业条件、工作场所作 业人员密度、生产过程中所涉及的危险物质的及数 量等方面存在的差别, 决定其具有不同的事故风 险。第二产业中的采矿业、建筑业和制造业的行业 特点决定其具有高事故风险。例如煤矿井下存在瓦 斯、水害等灾害因素, 工作环境复杂, 作业条件特 殊, 且大量工人处于同一采区进行采掘, 易导致重 特大事故; 建筑业因需要进行高空作业、施工过程 需要大量起重机械设备以及复杂的地质条件而容 易引发高处坠落事故、机械伤害事故和坍塌事故;
复杂的制造业因生产工艺常常涉及高温、高压, 生 产或使用危险材料而容易引发火灾、爆炸和毒物泄 漏扩散等事故。而第三产业的大多数行业特点决定 其具有低事故风险, 由于人员在低风险环境中工 作, 所接触的物质危险性低, 引发人身伤害事故的 概率和严重度均较小。

\section{3. 第二产业部分行业风险分析}

2006-2010 年, 煤矿、非煤矿山、建筑业和制 造业四个事故风险高的行业每年事故死亡人数 (如 表 4 所示）占工矿商贸领域事故死亡人数的总量分 别为 $88.9 \% 、 87.1 \% 、 87.1 \% 、 86.1 \%$ 和 $88.9 \%$ 。

表 4 2006-2010 年我国工矿商贸部分行业事故死亡人数

\begin{tabular}{llllll}
\hline 行业 & 年份 & & & & \\
\hline & 2006 & 2007 & 2008 & 2009 & 2010 \\
\hline 煤矿 & 4746 & 3786 & 3215 & 2631 & 2433 \\
非煤矿山 & 2277 & 2188 & 2068 & 1542 & 1271 \\
建筑业 & 2546 & 2722 & 2702 & 2760 & 2769 \\
制造业 & 3244 & 3393 & 3225 & 2993 & 2966 \\
工矿商贸合计 & 14412 & 13886 & 12865 & 11532 & 10616 \\
\hline
\end{tabular}

2006-2010 年, 我国原煤产量由 23.25 亿吨增长 到 32.5 亿吨, 年均增长 $8.7 \%$, 煤矿事故死亡人数 由 4746 人下降到 2433 人, 年均下降 $15.4 \%$, 原煤 生产在满足国民经济快速发展对能源大量需求的 同时, 安全生产形势逐步好转, 但事故死亡人数与
重特大事故起数仍较多（2006-2010 年煤矿重特大 事故起数分别为 $39 、 28 、 38 、 20$ 和 24）, 尤其是 特别重大事故给煤矿安全生产带来较大负面影响。 2006-2010 年我国原煤产量与煤矿事故死亡人数如 图 1 所示。

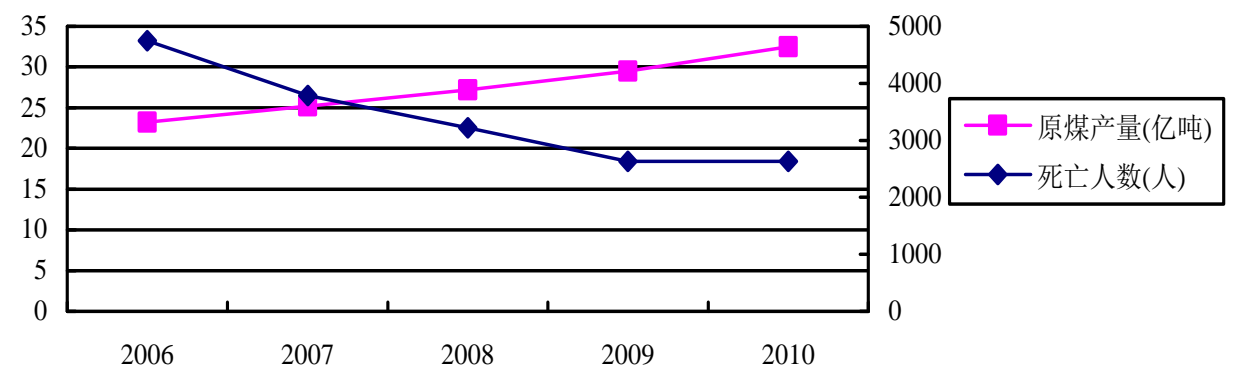

图 1 2006-2010 年我国原煤产量与煤矿事故死亡人数

2006-2010 年, 我国建筑业实现增加值由 12409 亿元增长到 26451 亿元, 年均增长 $20.8 \%$, 建筑业 在实现增加值翻番的同时, 建筑事故死亡人数由 2546 人增长到 2769 人, 事故死亡人数居高不下、
波动较小, 事故死亡人数呈上升趋势, 安全形势严 峻, 安全生产问题十分突出。2006-2010 年我国建 筑业增加值与建筑事故死亡人数如图 2 所示。 


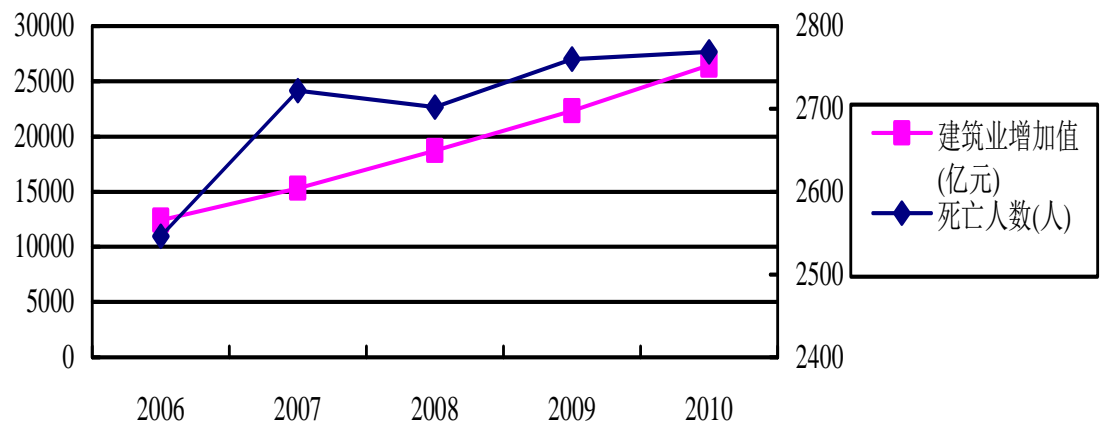

图 2 2006-2010 年我国建筑业增加值与建筑事故死亡人数

由以上数据分析可知, 近 5 年来, 我国经济在 实现较快增长的同时, 安全生产状况总体稳定, 但 部分行业安全生产形势不容乐观, 表现在建筑业安 全生产形势十分严峻, 制造业事故死亡人数较多, 采矿业安全生产状况虽实现逐步好转, 但事故死亡 人数和重特大事故起数依然较多, 这 3 个行业仍然 是事故多发的高风险行业。

\section{4. 三次产业的发展过程与事故变化趋势}

\section{1. 我国的产业发展过程与安全生产状况}

建国初期，第一产业比重最大，农业实现的增 加值最高, 为了发展经济, 我国开始制订并实施 5 年规划, 优先发展重工业, 使第二产业的比重快速 上升，第一产业的比重逐步下降，1950-1977 年间， 第一产业和第二产业的比重波动较大, 并呈此消彼 长的态势, 第三产业的比重变化较小。
改革开放后的 1978-1984 年间, 我国对产业结构进 行了调整, 1984 年第一、第二和第三产业的比重分 别为 32.1\%、43.1\%和 24.8\%, 总体特点是第一产业 比重提高, 第二产业比重趋于下降; 1985-1992 年 间, 第三产业的比重迅速上升, 1992 年第一、第二 和第三产业的比重分别为 $21.8 \%$ 、43.4\%和 34.8\%; 1993 年至今, 我国产业结构变化的总体特点是第一 产业的比重不断下降, 第二、第三产业的比重不断 上升。近十年来, 我国经济处在高速发展时期, 国 内生产总值由 1999 年的 82054 亿元增长到 2010 年 的 397983 亿元, 年均增长 15.4\%, 经济总量是 1999 年的近 5 倍, 其中第二产业的增加值一直占国内生 产总值的 50\%左右。 ${ }^{7-10} 1949-2010$ 年我国三次产业 所占比重与工矿商贸事故死亡人数的变化如图 3 所 示。

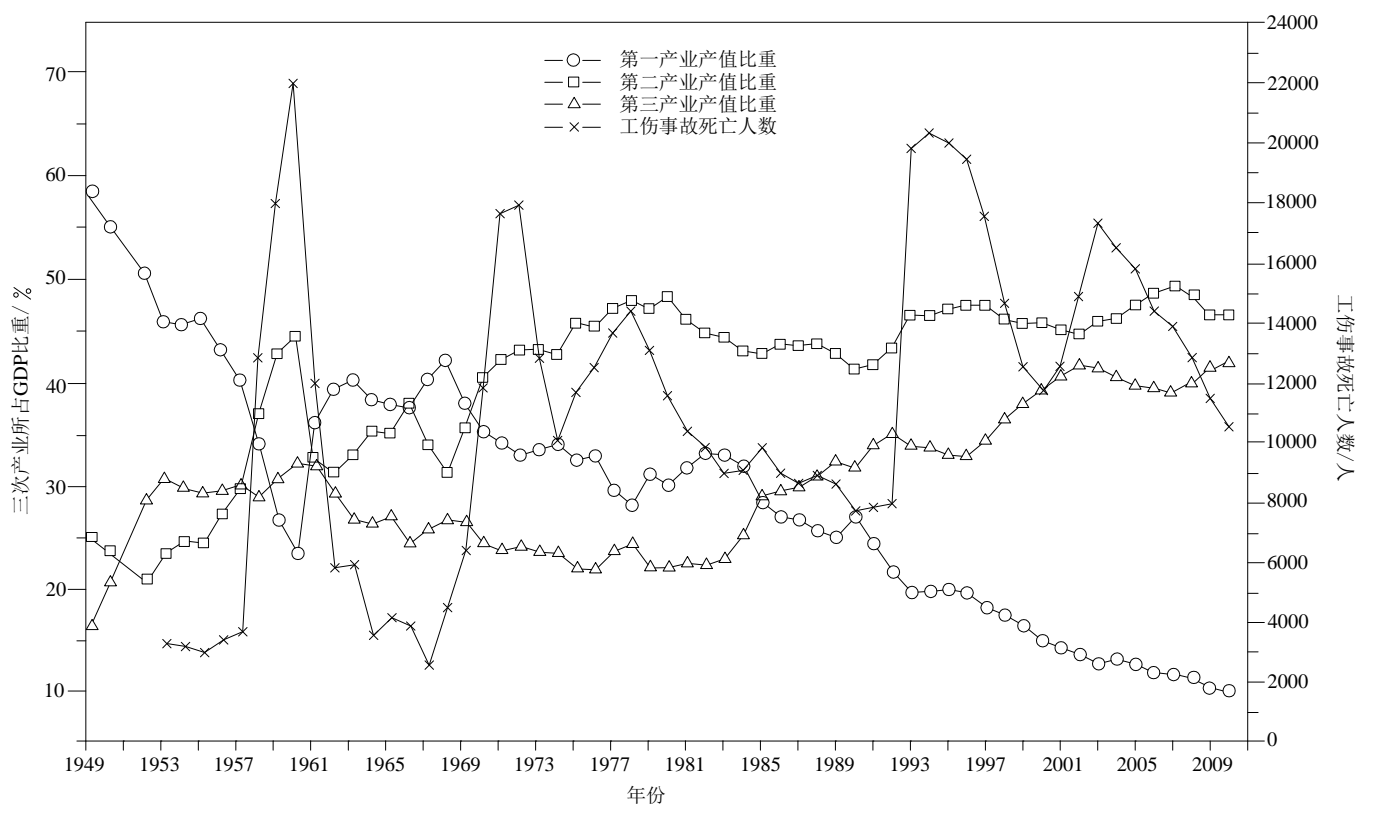

图 3 1949-2010 年我国三次产业所占比重与工矿商贸事故死亡人数

Published by Atlantis Press

Copyright: the authors 
由图 3 可知, 建国以来我国工矿商贸事故死亡 人数的波动与第二产业的变化趋势基本相同, 5 次 事故高峰（1960 年、1973 年、1979 年、1995 年、 2003 年) 均出现在第二产业比重上升时期, 第二产 业比重下降时, 安全形势又逐步实现好转。

近年来, 随着加快转变经济发展方式和调整经 济结构、大力发展现代农业、改造提升制造业、加 快发展服务业等产业结构调整目标的提出 ${ }^{11,12}$, 第 二产业所占比重不断减少, 第三产业所占比重持续 增加。与此同时, 第二产业不断转型升级, 针对煤 矿, 提出了建设大型煤炭基地、推进煤炭企业联合 重组等导向政策, 对于制造业, 提出了淘汰落后产 能、优化结构、发展先进装备制造业等转型升级方 针, 对于危险化学品, 提出了按照基地化、大型化、 一体化方向调整化学工业布局, 对于建筑业, 严格 了行业准入条件。第三产业的持续快速发展和第二 产业内部的转型升级使得安全生产状况持续稳定 好转。

\section{2. 主要发达国家的产业发展过程与安全生况}

目前, 第三产业在美国全部经济活动中的比重 已超过 $80 \%$, 在欧洲和日本经济中所占的比重已超 过 70\%, 并呈上升趋势。美国三次产业发展过程中, 在第二产业所占比重较大时期, 建筑业、制造业等 产业高速发展, 出现过事故频发、工伤人数居高不 下的情况, 随着第三产业所占比重的增加, 安全生 产形势逐步改善, 现在工伤事故已经下降到较低的 水平。日本也经历了同样的过程, 20 世纪 50 年代 以后, 随着制造业的兴起, 其安全生产问题突显, 工伤事故死亡人数剧增, 1961 年工伤事故死亡人数 达到了历史最高的 6712人, 1956-1973 年完成了重 化工业的调整，1974-1980 年完成了知识密集化和 高附加价值化的调整, 随着产业的不断发展、第三 产业所占比重的增加, 以及所采取的相关技术、监 管等措施, 工伤事故逐步得到控制, 从 1998 年起 其工伤死亡人数已控制在 2000 人以下。13-16

\section{3. 三次产业发展与事故变化趋势的关系}

由国内外三次产业的发展过程与事故变化趋 势的分析可知, 在第二产业迅速发展、所占比重较 大时期, 工伤事故伤亡人数多, 安全生产形势严峻, 当进行产业结构调整并使第三产业的比重明显增 加后, 安全生产形势明显改善, 大力发展第三产业 有利于减少高风险行业从业人数, 规避高风险行 业。

\section{5. 结束语}

不同行业的特点决定了其固有的伤亡事故风 险, 采矿业、建筑业和制造业是现阶段我国事故多 发的高风险行业, 3 个行业的事故死亡人数占工矿 商贸领域事故死亡人数的 $86 \%$ 以上。
安全生产水平与产业发展状况密切相关, 事故 高发期多出现在第二产业比重的增加期, 而第三产 业比重的增加有助于改善安全生产状况。目前我国 正处于产业结构调整的关键时期, 大力发展第三产 业, 提高第三产业的比重和水平, 减少高风险行业 从业人数, 是改善我国安全生产状况的根本途径。

现阶段第二产业仍是我国国民经济的重要支 柱, 比重仍较大, 在短时间内难以根本改变, 应继 续推动第二产业转型升级, 依靠科技进步和技术创 新, 淘汰落后工艺、技术与装备, 优化原材料工业, 发展先进装备制造业, 提升消费品工业, 对于第二 产业内的高危行业, 实行严格的安全准入制度和从 业人员安全资格制度, 构建安全、稳定的第二产业 体系。

大力发展安全产业, 依靠安全科技和安全装 备, 提高三次产业的安全保障能力, 形成安全检测 监控、应急救援装备、个体防护用品、本质安全化 装备与材料、安全培训、评价与咨询服务等产业, 实现安全发展。

\section{致谢}

本论文的研究工作得到了国家安全生产监督 管理总局课题 “安全发展本质内涵及政策措施研 究” 的资助。

\section{参考文献}

1. General Administration of Quality Supervision, Inspection and Quarantine of the People's Republic of China, GB/T 4754-2011 Sector Classification of National Economy. (China Standards Publishing House, Beijing, 2011).

国家质量监督检验检疫总局. GB/T 4754-2011 国民经 济行业分类. 北京: 中国标准出版社, 2011.

2. Z. Z. Wu, Discussion on the understanding and countermeasures of promoting work safety development, Journal of Safety Science and Technology, S(4) (2008): 118-122. 吴宗之, 促进安全发展的若干认识与对策探讨, 中国 安全生产科学技术, S(4) (2008): 118-122.

3. Z. Z. Wu, Study on some strategy problems of China's work safety by 2020, Journal of Safety Science and Technology, 3(1) (2007): 3-7.

吴宗之, 面向 2020 年我国安全生产的若干战略问题 的思考, 中国安全生产科学技术, 3(1) (2007): 3-7.

4. X. Z. Wang, Report on occupational safety vs economic and social development. (China Coal Industry Publishing House, Beijing, 2006).

王显政, 安全生产与经济社会发展报告, 北京: 煤炭 工业出版社, 2006.

5. National Bureau of Statistics of China, Statistical communiqué of national economic and social development of the People's Republic of China from 1999 to 2011.

中华人民共和国国家统计局, 中华人民共和国 1999-2011 年国民经济和社会发展统计公报.

6. State Administration of Work Safety, Accident statistical communiqué of State Administration of Work Safety from 2006 to 2011.

Published by Atlantis Press

Copyright: the authors 
国家安全生产监督管理总局, 2006-2011 年国家安全 生产监督管理总局事故统计年报.

7. Y. N. Li, The relationship between economic reforms, economic growth and industrial structure adjustment, The Journal of Quantitative \& Technical Economics, (12) (1988): 3-9.

厉以宁, 经济改革、经济增长与产业结构调整之间的 关系, 数量经济技术经济研究, (12) (1988): 3-9.

8. S. L. Zhou, A few questions of China's industrial structure adjustment and upgrading, China Industrial Economics (7) (1998): 22-29.

周叔莲, 我国产业结构调整和升级的几个问题, 中国 工业经济, (7) (1998): 22-29.

9. Y. Y. Song, W. R. Pan, Discussion of the characteristics and evolvement direction of current industrial structure of China, HLJ Foreign Economic Relations \& Trade (1) (2010): 59-60.

宋迎迎, 潘文荣, 论我国当前产业结构的特点及演化 方向，黑龙江对外贸易, (1) (2010): 59-60.

10. L.Song, Dynamic econometric analysis on relativity between accident disasters and economic growth \& its application, doctor thesis, Beijing: China University of Mining and Technology(Beijing), (2010): 61-72.

宋利, 事故灾害与经济增长关联性动态计量分析技 术及应用, 中国矿业大学 (北京) 博士学位论文[D], (2010): 61-72.

11. 2011 年两会温家宝总理政府工作报告全文[EB/OL]. 2011-03-07.http://news.hexun.com/2011-03-07/127754 083.html

12. Research Group of Institute of Industrial Economics CASS, A study on the adjustments and upgrades to China's industrial structure during the 12th Five-Year Plan period, China Industrial Economics (1) (2010): 5-23.

中国社会科学院工业经济研究所课题组, “十二五”时 期工业结构调整和优化升级研究, 中国工业经济, (1) (2010): 5-23.

13. C. X. Jin, M. Wang, The new trend of industrial structure adjustment in major advanced countries in the world, Management. (1-2) (2008): 99-100.

金成晓, 王猛, 世界主要发达国家产业结构调整的新 趋势,管理, (1-2) (2008): 99-100.

14. Q. Yuan, C. Y. Liu, Adjustment of industrial structure and development of service industry in the U. S. World Economy Study .(2) (2007): 57-63.

袁奇, 刘崇仪, 美国产业结构变动与服务业的发展, 世界经济研究, (2) (2007): 57-63.

15. W. L. Zhao, C. B. Wu, Change of industrial structure and the function of foreign capital in the Asian-Pacific region. (Xiamen University Press, Xiamen, 1992) 赵文骝，吴崇伯，亚太地区产业结构变化与外资的作 用, 厦门: 厦门大学出版社, 1992.

16. D. Y. Song, T. Z. Zhang, Optimize industrial development through environmental protection Taking Japan's industrial restructuring for example Technoeconomics \& Management Research. (3) (2012): 115-119.

宋丹瑛, 张天柱, 论资源环境优化产业升级一以战后 日本产业结构调整为例, 技术经济与管理研究, (3) (2012): 115-119. 